\title{
Quantitative CT-based image registration metrics provide different ventilation and lung motion patterns in prone and supine positions in healthy subjects
}

Kyung Min Shin ${ }^{1+}$, Jiwoong Choi ${ }^{2,3+}$, Kum Ju Chae ${ }^{4}$, Gong Yong Jin ${ }^{4}$, Ali Eskandari ${ }^{5}$, Eric A. Hoffman ${ }^{5,6,7}$, Chase Hall ${ }^{2}$, Mario Castro ${ }^{2}$ and Chang Hyun Lee ${ }^{5,8^{*}}$ (D)

\begin{abstract}
Background: Previous studies suggested that the prone position (PP) improves oxygenation and reduces mortality among patients with acute respiratory distress syndrome (ARDS). However, the mechanism of this clinical benefit of PP is not completely understood. The aim of the present study was to quantitatively compare regional characteristics of lung functions in the PP with those in the supine position (SP) using inspiratory and expiratory computed tomography (CT) scans.

Methods: Ninety subjects with normal pulmonary function and inspiration and expiration $C T$ images were included in the study. Thirty-four subjects were scanned in PP, and 56 subjects were scanned in SP. Non-rigid image registration-based inspiratory-expiratory image matching assessment was used for regional lung function analysis. Tissue fractions (TF) were computed based on the CT density and compared on a lobar basis. Three registrationderived functional variables, relative regional air volume change (RRAVC), volumetric expansion ratio $(J$ ), and threedimensional relative regional displacement $\left(s^{*}\right)$ were used to evaluate regional ventilation and deformation characteristics.
\end{abstract}

Results: $J$ was greater in PP than in SP in the right middle lobe $(P=0.025)$, and RRAVC was increased in the upper and right middle lobes $(P<0.001)$. The ratio of the TF on inspiratory and expiratory scans, $J$, and RRAVC at the upper lobes to those at the middle and lower lobes and that ratio at the upper and middle lobes to those at the lower lobes of were all near unity in PP, and significantly higher than those in SP $(0.98-1.06$ vs $0.61-0.94, P<0.001)$.

\footnotetext{
* Correspondence: changhyun.lee@snu.ac.kr

${ }^{\dagger}$ Kyung Min Shin and Jiwoong Choi contributed equally to this work.

${ }^{5}$ Department of Radiology, University of lowa, lowa City, USA

${ }^{8}$ Department of Radiology, Seoul National University College of Medicine,

Institute of Radiation Medicine, Seoul National University Hospital, 101

Daehak-ro, Jongnogu, Seoul 03080, South Korea

Full list of author information is available at the end of the article
}

C C The Author(s). 2020 Open Access This article is licensed under a Creative Commons Attribution 4.0 International License, which permits use, sharing, adaptation, distribution and reproduction in any medium or format, as long as you give appropriate credit to the original author(s) and the source, provide a link to the Creative Commons licence, and indicate if changes were made. The images or other third party material in this article are included in the article's Creative Commons licence, unless indicated otherwise in a credit line to the material. If material is not included in the article's Creative Commons licence and your intended use is not permitted by statutory regulation or exceeds the permitted use, you will need to obtain permission directly from the copyright holder. To view a copy of this licence, visit http://creativecommons.org/licenses/by/4.0/ The Creative Commons Public Domain Dedication waiver (http://creativecommons.org/publicdomain/zero/1.0/) applies to the data made available in this article, unless otherwise stated in a credit line to the data. 
(Continued from previous page)

Conclusion: We visually and quantitatively observed that PP not only induced more uniform contributions of regional lung ventilation along the ventral-dorsal axis but also minimized the lobar differences of lung functions in comparison with SP. This may help in the clinician's search for an understanding of the benefits of the application of PP to the patients with ARDS or other gravitationally dependent pathologic lung diseases.

Trial registration: Retrospectively registered.

Keywords: Acute respiratory distress syndrome (ARDS), Prone positioning, Quantitative computed tomography (QCT), Lung motionography

\section{Background}

The concept of prone positioning of patients on mechanical ventilation for ARDS was proposed in the 1970s and has been regarded as a rescue strategy. Prone position (PP) has been shown to improve oxygenation [1-4] and survival [5-7] in patients with ARDS. Despite the clinical benefits of proning a patient, the mechanism of improvement is not completely understood. The differences in the supine position (SP) versus PP might be related to some anatomical and physiological parameters. From the gravity oriented SP gradients in lung expansion and the considerable reduction in this gradient, not just the reversal of the expansion gradient, in PP allows one to deduce that pleural pressure gradient from nondependent to dependent regions are less in the PP, in part by gravitational effects, reducing the superimposed pressure of both the heart and possibly the abdomen. In a comparative physiology study, the authors concluded that the support of the heart by the lungs in the SP versus support of the heart by the sternum in the PP, rather than shape changes in the rib cage and diaphragm, may be responsible for the differences in resting, recumbent lung expansion gradients [8]. More recent works in humans have confirmed the reversal and considerable reduction in resting gradient in ventral-dorsal lung expansion when shifting a human from the supine to the prone body posture $[9,10]$. In contrast to effects on lung aeration, pulmonary blood flow is constantly directed dorsally in normal and injured lungs in both the SP and the PP $[3,11]$. Therefore, the PP improves ventilationperfusion matching [12], and contributes to improvement in oxygenation. During mechanical ventilation, the more uniform distribution of lung strain allows for recruitment at lower positive pressure, a reduction in regional shear strain, and thus less ventilator-induced lung injury (VALI) $[13,14]$.

On the basis of these observations, the analysis of regional heterogeneity of aeration and strain, taking advantage of advances in CT technologies, is crucial for understanding the mechanism of the clinical benefit of the PP. Advances in quantitative computed tomography (CT) imaging and data analysis techniques allow clinicians to assess regional functional and mechanical metrics such as ventilation and regional lung deformation in considerably greater detail [15-17], and these techniques provide maps of regional ventilation and lung stretch between pairs of inspiratory and expiratory images in three-dimension $[18,19]$. To obtain objective results of CT quantitative analysis, a method of automated lung CT segmentation is needed. However, the segmentation of ARDS involvement requires time and experience because consolidation or atelectasis of the lung limits structural reference contrast against the chest wall $[18,20]$. Furthermore, transport of critically ill patients to a CT scanner is problematic [21]. Although densitybased CT quantification of the SP versus PP has been explored in experimental [22] and human studies [13, 23-25], functional and mechanical CT metrics have not been used to compare the differences between the SP and the PP.

Therefore, we hypothesized that through the use of three-dimensional (3D) CT image registration in healthy subjects, quantification of regional ventilation metrics and visualization of the regional lung motion could clarify the benefit of the PP demonstrated in ARDS. The purpose of this study was to quantitatively compare the regional characteristics of lung functions on a lobar basis between PP and SP with the use of paired inspiratory and expiratory CT scans.

\section{Methods}

Our institutional review board approved this retrospective study and waived the requirement for informed consent.

\section{Patients}

We recruited patients with normal pulmonary function test who had undergone chest CT scanning from the data set that were originally collected for quantitative analysis of lungs in normal subjects [26]. We used the following inclusion criteria: (1) availability of both inspiratory and expiratory CT scans; (2) no known history of lung disease or surgery; and (3) absence of nodules or less than 5 nodules $(<4 \mathrm{~mm})$. Fifty-six subjects $(26 \mathrm{men}$, 30 women; mean age, $50.5 \pm 14.7$ years) were included retrospectively for the SP. In addition, we retrospectively 
collected 34 subjects (16 men, 18 women; mean age, $47.4 \pm 10.6$ years) for the PP who performed follow up CT in PP to differentiate subpleural nodules or interstitial abnormality from gravity-dependent atelectasis or nodular atelectasis in the dependent regions of the lungs for the clinical purposes.

\section{CT acquisition}

All patients underwent 128 multidetector CT scanning (Somatom Definition Flash; Siemens Healthcare, Forchheim, Germany) under full inspiration and full expiration. CT parameters were as follows: tube voltage (120 $\mathrm{kVp}$ ), tube current (inspiration, $110 \mathrm{mAs}$; expiration, $50 \mathrm{mAs})$, slice thickness $(1.0 \mathrm{~mm})$, and reconstruction interval $(1.0 \mathrm{~mm})$, reconstruction algorithm $(\mathrm{B} 35 \mathrm{f})$, rotation time $(0.5 \mathrm{~s})$. Inspiratory scans (IN) were obtained at total lung capacity (TLC), and expiration scans (EX), at functional residual capacity (FRC).

\section{Image registration, regional air volume change, and lung deformation}

Figure 1 is the flow chart of the steps involved from image acquisition to the regional lung functional maps. All volumetric CT images at inspiration and expiration were segmented with the use of VIDA Apollo pulmonary workstation, version 2.0 (VIDA Diagnostics, Coralville, IA, USA). The mass-preserving nonrigid image registration technique was employed to match local lung regions (voxels) of inspiratory and expiratory $\mathrm{CT}$ images
[15]. Local air and tissue volumes as well as tissue fraction (TF) were computed in voxels based on the CT density and compared on a lobar basis [16]. Image registration provided local displacement vectors between the matched points in the paired two images and displacement magnitude was normalized by the cubic root of lung volume change between two images to reduce the influence of different inflation levels among subjects (Fig. 2). Normalized 3D relative regional displacement was denoted by $s^{*}$. From matched units of local lung parenchyma on an acinar scale, 3D displacement vectors from expiration to inspiration were computed. Local volume change ratio of inspiratory to expiratory images (computed by Jacobian determinant, $J$ ) and relative regional air volume change (RRAVC) were derived to quantify lung deformation [27, 28]. Thus, $s^{*}, J$, and RRAVC were indicators of preferential lobar nonuniform stretch (a measure of the magnitude of direction preference in volume change), local expansion (a measure of regional volume change), and airvolume change (a measure of regional ventilation), respectively [16]. Voxel-scale local lung variables were presented in approximately 30,000 acinar-scale parenchymal units to exhibit lung function distribution. The ratio of the CT variables at the upper lobes to those at the middle and lower lobes (U/ML) and the ratio of those at the upper and middle lobes to those at the lower lobes $(\mathrm{UM} / \mathrm{L})$ were calculated in PP and SP, respectively.

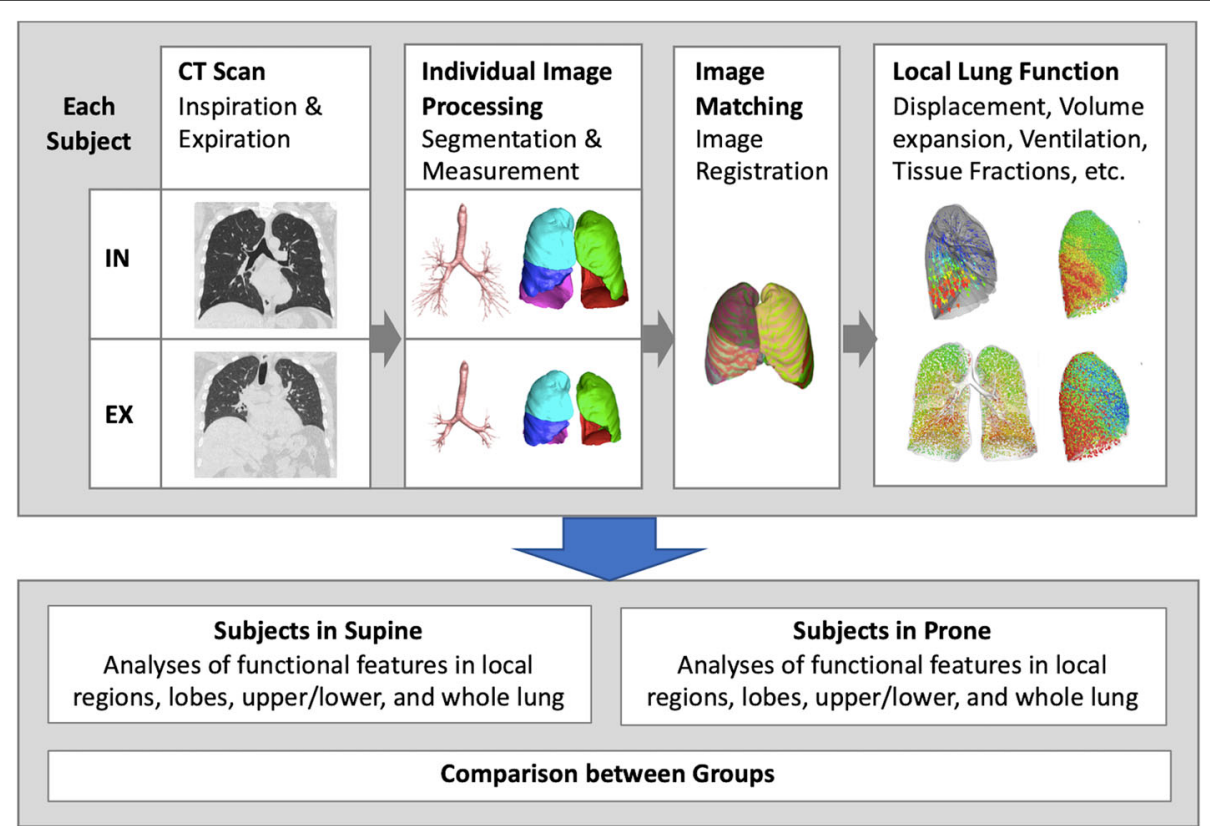

Fig. 1 Flow chart of the steps involved from image acquisition to the regional lung functional maps, and further to the comparison between supine and prone groups 

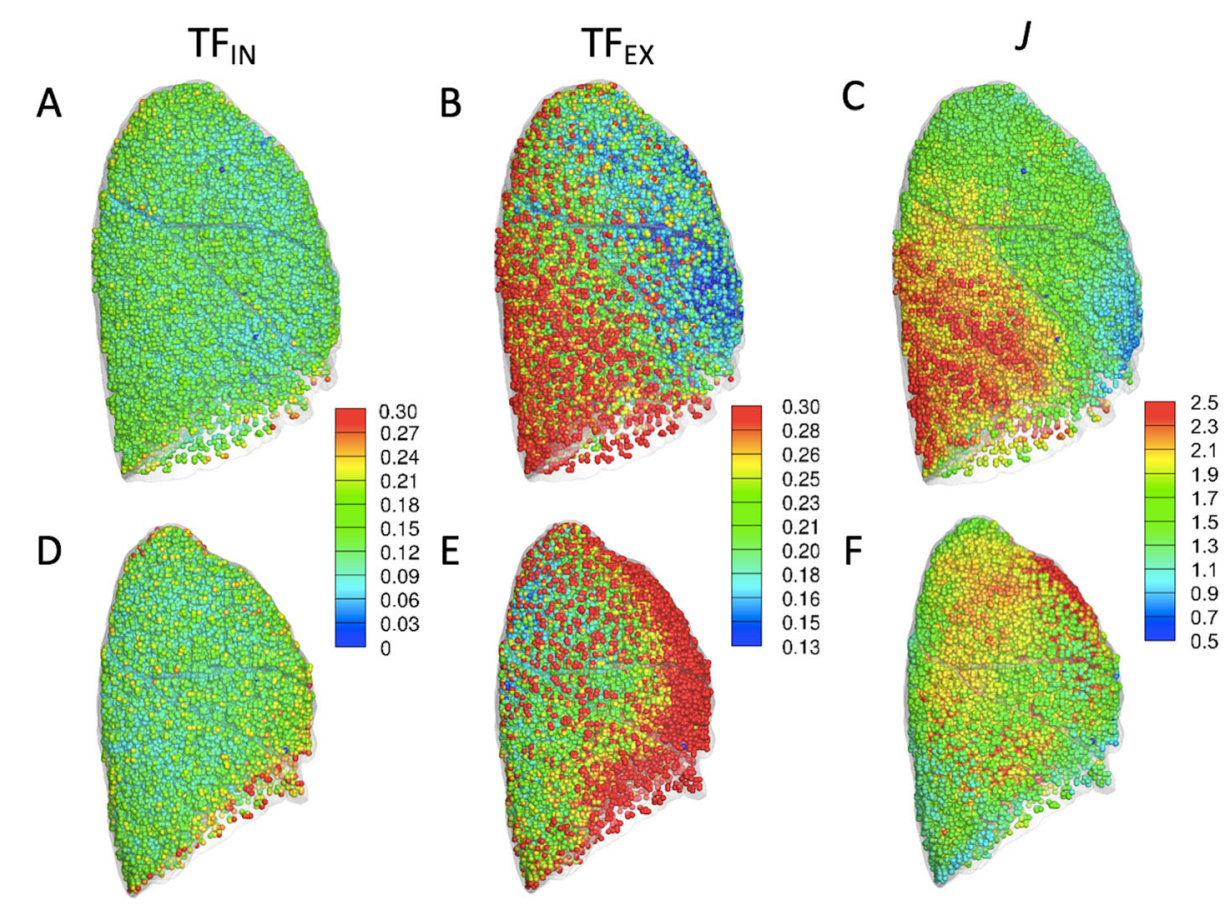

Fig. 2 Demonstration of inspiratory ( $\mathbf{a}$ and $\mathbf{d}$ ) and expiratory (b and $\mathbf{e}$ ) tissue fraction (TF $\mathbb{I N}_{\mathrm{N}}$ and $\mathrm{TF}_{\mathrm{Ex}}$, respectively) maps and local expansion ( $)$ map (c and $\mathbf{f}$ ) in supine (a-c) and prone (d-f) positions. $T F_{\mathbb{N}_{N}} T_{E X}$, and $J$ were computed in local lung parenchymal volumetric units at an acinar scale and were colored according to a rainbow scale. $\mathrm{TF}_{\mathbb{N}}$ and $\mathrm{TF}_{\mathrm{EX}}$ are plotted in the same scale for comparison between inspiration and expiration. Since the summation of both air and tissue fractions is equal to unity, the decrease in tissue fraction implies an increase in air fraction. $J$ is computed as inspiratory-to-expiratory volume ratio at matched parenchymal units

\section{Statistical analysis}

Data were expressed as means ( \pm standard deviations). Student's $t$-tests were used to compare the functional metrics of inspiratory and expiratory CT scans between the SP and the PP. A P value of less than 0.05 was considered significant. Software R (R Foundation for Statistical Computing, Vienna, Austria) was used for statistical analyses.

\section{Results}

\section{Tissue fractions in supine vs prone}

Table 1 summarizes the results of the changes in TFs according to the lobes in the SP and PP. TF on inspiratory

Table 1 Results of Tissue Fractions in Prone Versus Supine Positions

\begin{tabular}{lllll}
\hline Variable & Region & Prone & Supine & $P$ value \\
\hline TF $_{\text {IN }}$ & Upper & 0.151 & 0.150 & 0.713 \\
& RML & 0.167 & 0.142 & $1.8 \times 10^{-3}$ \\
& Lower & 0.147 & 0.163 & 0.003 \\
TF $_{\text {EX }}$ & Upper & 0.253 & 0.235 & 0.127 \\
& RML & 0.277 & 0.211 & $1.5 \times 10^{-6}$ \\
& Lower & 0.243 & 0.295 & 0.001 \\
\hline
\end{tabular}

All values are expressed as means. $R M L$ Right middle lobe, $T F_{I N}$ Tissue fraction on inspiratory scan, $T F_{E X}$ Tissue fraction on expiratory scan scans $\left(\mathrm{TF}_{\mathrm{IN}}\right)$ was decreased in the lower lobes $(P<0.003)$ and increased in the right middle lobe in the PP $(P<$ $0.001)$. TF on expiratory scans $\left(\mathrm{TF}_{\mathrm{EX}}\right)$ was greater in the right middle lobes and the whole lung $(P<0.01)$ but not in the lower lobes $(P>0.05)$ in the PP. UM/L and U/ML of $\mathrm{TF}_{\mathrm{IN}}$ and $\mathrm{TF}_{\mathrm{EX}}$ were all near unity in $\mathrm{PP}$, whereas they are smaller in the SP $\left(P<1.0 \times 10^{-7}\right.$; Table 2$)$. In both SP and PP, the inspiratory image shows a relatively uniform distribution of TF that is attributable to the full recruitment of alveoli (Fig. 2a and d). On expiration, the gradient toward gravitationally dependent dorsal and basal regions in SP was shifted toward ventral regions (Fig. 2b and e).

Table 2 Upper to Lower Lobes Ratio of TF $F_{N}, T F_{E X}$, and $J$ in Prone Versus Supine Positions

\begin{tabular}{|c|c|c|c|c|c|c|}
\hline \multirow[t]{2}{*}{ Variable } & \multicolumn{3}{|l|}{ UM/L } & \multicolumn{3}{|l|}{ U/ML } \\
\hline & Prone & Supine & $P$ value & Prone & Supine & $P$ value \\
\hline$\overline{\mathrm{TF}} \mathrm{IN}_{\mathrm{N}}$ & 1.06 & 0.91 & $1.4 \times 10^{-12}$ & 1.02 & 0.94 & $2.1 \times 10^{-8}$ \\
\hline $\mathrm{TF}_{\mathrm{EX}}$ & 1.06 & 0.79 & $3.6 \times 10^{-19}$ & 1.02 & 0.84 & $3.7 \times 10^{-17}$ \\
\hline$J$ & 1.00 & 0.86 & $2.4 \times 10^{-24}$ & 1.01 & 0.89 & $2.1 \times 10^{-19}$ \\
\hline RRAVC & 0.99 & 0.61 & $6.6 \times 10^{-4}$ & 0.98 & 0.78 & $4.8 \times 10^{-9}$ \\
\hline
\end{tabular}

All values are expressed as means. J Jacobian, RRAVC Relative regional air volume change, $T F_{E X}$ Tissue fraction on expiratory scan, $T F_{I N}$ Tissue fraction on inspiratory scan, U/ML Ratio of variables of upper lobe to those of middle and lower lobes, UM/L Ratio of variable of upper and middle lobes to that of lower lobe 
Regional lung volumetric expansion ratio $(J)$ and motion $\left(s^{*}\right)$ in supine vs prone

In the PP, $J$ was decreased in the lower lobes $(P<0.005)$ and increased in the right middle lobe $(P=0.025$; Table 3), as demonstrated in Fig. 2f compared with Fig. 2c. In the SP, the regional displacement gradient increased toward dorsal-basal regions. However, it was reduced and shifted toward anterior regions in the PP (Fig. 3). From one subject who had both supine and prone CTs, motionography in an axial view from the bottom (diaphragm) was compared in Fig. 4. The eminent decrease of regional difference and a slight decrease of anterior-posterior distance were observed. U/ML ratios of $s^{*}$ were decreased in the PP $(P=0.004)$, but $\mathrm{UM} / \mathrm{L}$ ratios were not. $\mathrm{UM} / \mathrm{L}$ and $\mathrm{U} / \mathrm{ML}$ ratios of $J$ were near unity and significantly greater than those in SP $\left(P<1.0 \times 10^{-18}\right.$; Table 2$)$.

\section{RRAVC in supine vs prone}

RRAVCs increased in the upper lobes $\left(P=6.7 \times 10^{-6}\right)$ and decreased in the lower lobes $\left(P=3.3 \times 10^{-5}\right)$ in the $\mathrm{PP}$, in comparison with those in SP. Figure 5 shows RRAVC distributions in five different views in demonstrative subjects in supine and prone positions. In SP, a strong gradient toward gravitationally dependent regions is observed. On the contrary, the gradient is neutralized in PP, with a shift of ventilation contribution toward ventral regions. In the PP, UM/L and U/ML ratios of RRAVCs (0.99 and 0.98, respectively) were near unity and significantly higher than those in the SP $(0.61$ and 0.78 , respectively; $P \mathrm{~S}=6.6 \times 10^{-4}$ for $\mathrm{UM} / \mathrm{L}$ ratios and $4.8 \times 10^{-9}$ for U/ML ratios).

\section{Discussion}

In this study, we performed a quantitative analysis to compare regional characteristics of lung functions

Table 3 Regional volume expansion ratio and air volume change in prone versus supine positions

\begin{tabular}{lllll}
\hline Variable & Region & Prone & Supine & $\boldsymbol{P}$ value \\
\hline$J$ & LUL & 1.613 & 1.551 & 0.301 \\
& LLL & 1.600 & 1.809 & 0.001 \\
& RUL & 1.598 & 1.552 & 0.448 \\
& RML & 1.567 & 1.447 & 0.025 \\
RRAVC & RLL & 1.597 & 1.797 & 0.002 \\
& LUL & 1.040 & 0.891 & $7.6 \times 10^{-7}$ \\
& LLL & 1.069 & 1.270 & $4.8 \times 10^{-7}$ \\
& RUL & 1.012 & 0.890 & $6.4 \times 10^{-4}$ \\
& RML & 1.049 & 0.713 & $4.4 \times 10^{-19}$ \\
& RLL & 1.058 & 1.279 & $7.2 \times 10^{-4}$ \\
\hline
\end{tabular}

All values are expressed as means. J Jacobian, LLL Left lower lobe, LUL Left upper lobe, RLL Right lower lobe, RML Right middle lobe, RRAVC Relative regional air volume change, $R U L$ Right upper lobe between the SP and PP by using image registration applied to matched pairs of inspiratory and expiratory CT scans. We derived functional CT metrics by quantifying lung deformation and computed the regional tissue deformation and mechanics on a lobar basis. This study visualized that PP induced more uniform contributions of regional lung ventilation on RRAVC maps and a shift of 3D $s^{*}$ toward anterior regions on the 3D motionography. We calculated the ratio of functional measures in each lobe and found that the PP minimized the lobar differences in lung functions.

In several previous studies, researchers attempted to develop a hypothesis of homogeneous ventilation in the PP by using density-based CT analysis. Studies with standard CT volumetry showed that the vertical gradient CT density was attenuated when patients with ARDS were in PP $[8,24]$, and the cephalocaudal gradient was reduced in experimental animal models [22]. These results indicate that the PP induces a more uniform distribution of gas and tissue by reducing anteroposterior and cephalocaudal gradients. Other studies showed that the volume of overinflated lung mass decreased, whereas the volume of nonaerated or poorly aerated lung mass increased in the PP, which suggests that lung recruitment and homogeneity were enhanced in the PP [13, 23]. In this study, we computed tissue fractions $\left(\mathrm{TF}_{\mathrm{IN}}\right.$ and $\mathrm{TF}_{\mathrm{EX}}$ ) rather than the $\mathrm{CT}$ density-based volumetry to quantify the regional homogeneity.

The present study demonstrates that, in the PP, $\mathrm{TF}_{\mathrm{IN}}$ and $\mathrm{TF}_{\mathrm{EX}}$ were increased in the right middle lobe but decreased in the lower lobes in the PP $(P<0.05$; Table 1). In addition, $U M / L$ ratios of $T F_{I N}$ and $T F_{E X}$ were all near unity in the PP, and were significantly greater than those in the SP $\left(P<1.0 \times 10^{-7}\right)$. These findings corroborate the previous results from density-based CT volumetry studies with regard to homogeneity in the PP. This improvement in ventilatory homogeneity in ARDS leads to a decrease in the shunt fraction [3, 4], and in approximately $70 \%$ of patients, ventilation-perfusion mismatching and oxygenation were markedly improved in the PP $[3,4]$. However, improvement in oxygenation in the PP does not fully explain the decreased mortality of ARDS [29]. Thus, the survival benefit observed with the PP is assumed to be more related to a protective effect against VALI $[10,30]$. Indeed, recent data indicate that the paradigm of ARDS management has shifted from improving gas exchange to minimizing VALI and ensuring lung protection [31].

ARDS is characterized by a massive loss of lung aeration for tidal ventilation, which predominates in dorsal regions in the SP [32]. Hence, the mechanical distortion and regional overdistension caused by tidal ventilation develop in "ventral aerated lungs" in the SP, which is the most important determinant of VALI [33]. The PP has 

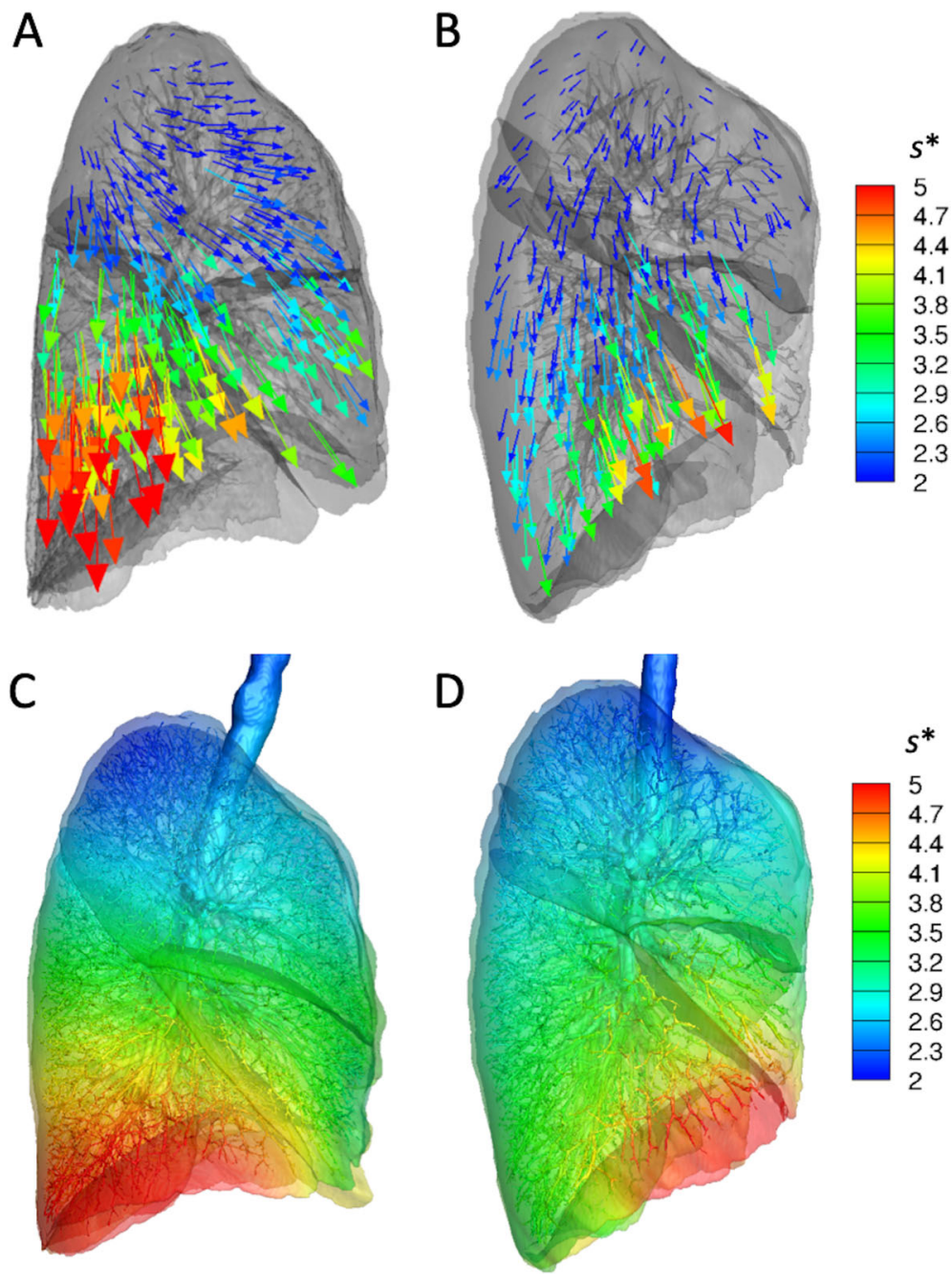

Fig. 3 Demonstration of regional lung motionography in supine and prone positions. Displacement vectors from expiration to inspiration (a and b) and normalized 3D displacement magnitude maps on entire lung regions ( $\mathbf{c}$ and $\mathbf{d}$ ) in supine position ( $\mathbf{a}$ and $\mathbf{c}$ ) and prone position (b and $\mathbf{d}$ ). For visual interpretation, three-dimensional displacement vectors were plotted and colored according to a rainbow scale by s* $^{*}$

been reported to delay and attenuate the progression of VALI in animal studies [14, 30], and a CT volumetric study in patients with ARDS also revealed that PP was an effective lung protective strategy that could possibly alleviate VALI [13]. However, these studies did not provide evidence of $\mathrm{CT}$ metrics with regard to reduced strain in the PP. A more recent experimental study with inspiratory and expiratory CT scans revealed that the PP alleviated lung injury by minimizing the patterns with suboptimal aeration and large tidal swings (termed "unstable inflation") [34]. The investigators employed parametric response maps, which have an advantage of spatial localization compared with simple density maps, and can depict regional heterogeneity. However, simple density difference measures are confounded by the effect of the baseline inflation of the target lung region. Therefore, we used the functional CT metrics of regional ventilation and tissue mechanics including $s^{*}, J$, and RRAVC, which enable us to detect additional heterogeneity of lung strain and stress over CT density map [16, 35].

Our results showed that UM/L and U/ML ratios of RRAVC and $J$ were all near unity in the PP and significantly higher in the PP than in the SP $\left(P_{\mathbf{S}}<0.001\right.$; Table 2). Moreover, the regional displacement gradient was reduced and shifted toward the anterior regions in the PP (Fig. 3). Because the loss of lung aeration is distributed mainly in the dorsal and caudal lungs in the SP [36, 37], these results together suggest that regional differences in strain between lung regions are reduced in the PP. Given that it is a crucial step to decrease lung strain in ARDS to prevent VALI, the PP could be an effective strategy of recruiting nonaerated lung and preventing overinflation. Nonetheless, the PP has been shown to be effective and 


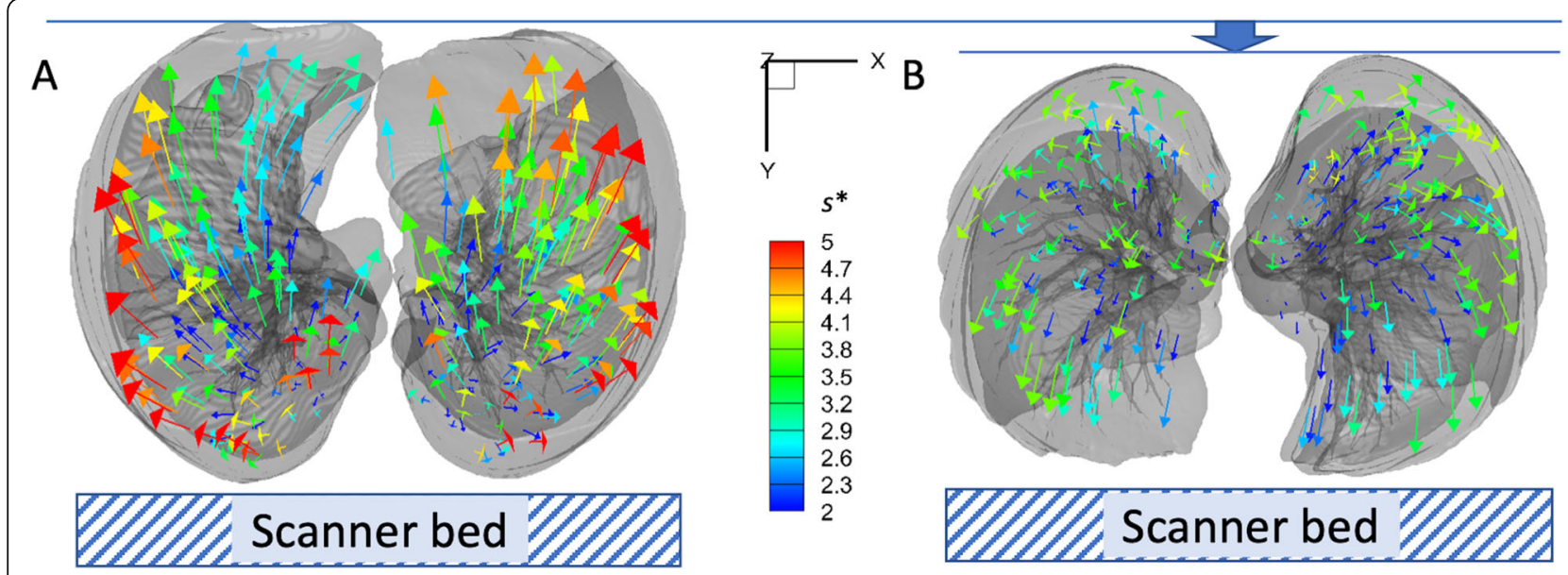

Fig. 4 Bottom view comparison of displacement vector distributions in (a) supine and (b) prone positions of the same subject (M, 53 yr) for demonstration

is recommended in only severe ARDS [6,38]. It is speculated that the PP benefits more hypoxemic patients with ARDS, who have more severe and heterogeneous lung injury and greater ventilation-perfusion mismatch. However, with increasing understanding of the heterogeneous pathophysiology of ARDS, identifying patients who will most benefit from the PP remains elusive [10]. Recently, lung morphology, assessed by CT images, has been suggested as a predictor of benefit from the PP, which indicates that gravity dependent ARDS is more likely to respond to the PP than is diffuse ARDS [13, 39]. Of note was that a lobar analysis in our study showed a trend for RRAVC and $J$ to increase in the right middle and upper lobes and to decrease in the lower lobes in the PP (Table 3). Moreover, our study included the 3D motionography and mapping of the regional lung homogeneity and strain. In the real-life clinical practice for ARDS, lung morphology assessments are not readily available and frequently misclassified [31], and so the visual information provided in this study could serve as a surrogate to apply personalized PP therapy in patients with gravity dependent ARDS.

This study had some limitations that need to be considered. First, a comparison of CT measures between the

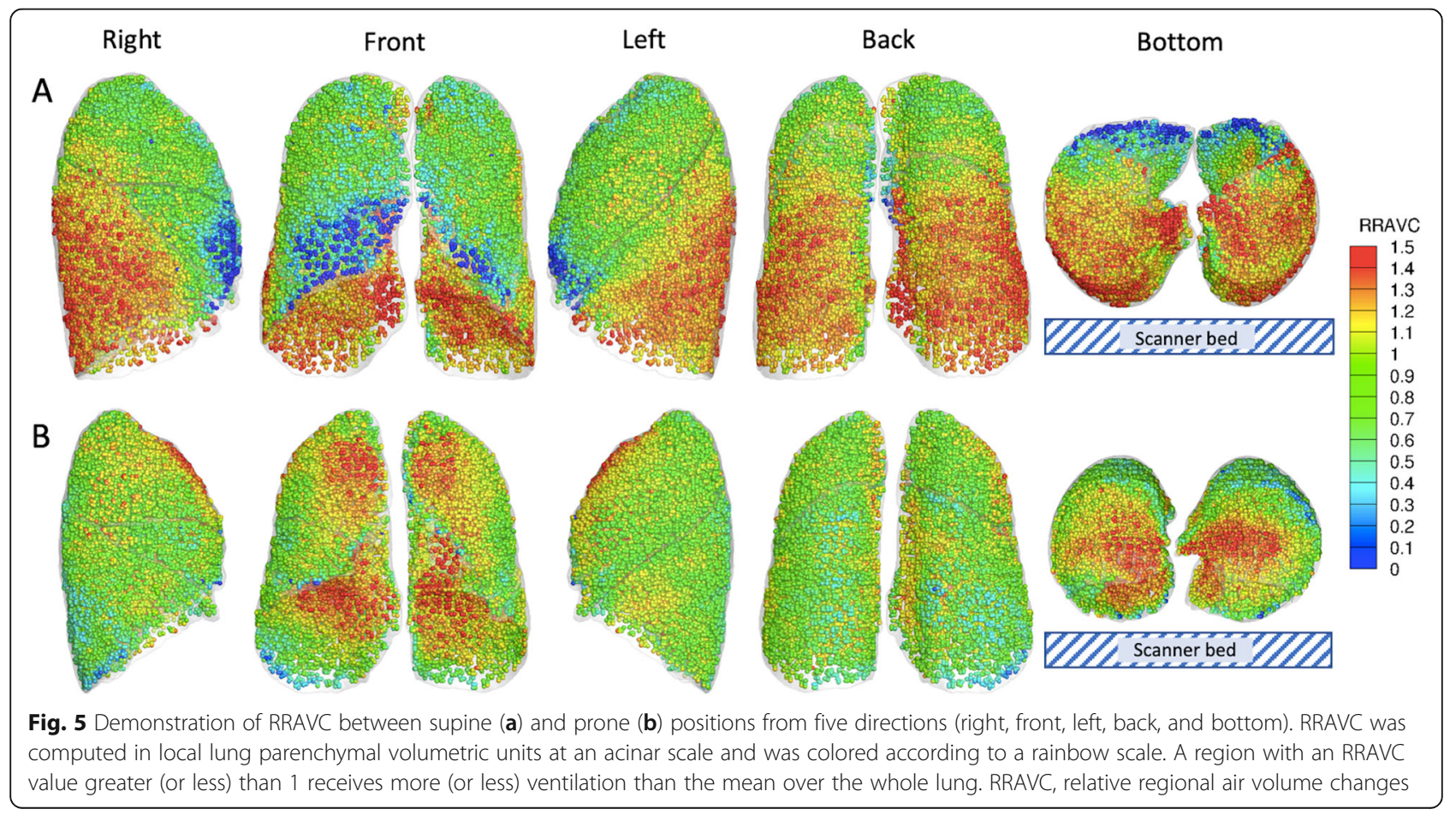


SP and PP was performed mostly in different subjects. Thus, intersubject variability may have affected CT measures. However, we included only subjects with normal lungs. In addition, the distributions of specific volume change and density have been demonstrated to be more homogeneous in healthy subjects than in patients with lung disease [40]. Second, this quantitative analysis was in healthy subjects with normal lungs, not in patients with ARDS. In addition, inspiratory scans were taken at TLC, i.e., with a volume excursion several times larger than the tidal volume used during mechanical ventilation. Hence, the effect of CT metrics extracted from homogeneous normal lungs taken at TLC could be a little different in heterogeneous ARDS during mechanical ventilation. Indeed, the PP is known to be effective only in severe ARDS, and identifying patients who would most benefit from the PP remains a clinical challenge [38]. Therefore, further research into the comparison of these regional ventilation and lung mechanics between the SP and PP in ARDS is warranted.

\section{Conclusions}

In conclusion, we visually and quantitatively observed that the PP not only induced more uniform contributions of regional lung ventilation along the ventraldorsal axis but also minimized the lobar differences in lung functions compared with the SP. These findings along with the methodologies used in this study may help in the clinician's search for an understanding of the benefits of the application of PP to the patients with ARDS or other gravitationally influenced pathologic lung diseases.

\section{Abbreviations}

ARDS: Acute respiratory distress syndrome; CT: Computed tomography; FRC: Functional residual capacity; J: Jacobian determinant; PP: Prone position; RRAVC: Relative regional air volume change; $s^{*}$ : Three-dimensional relative regional displacement; SP: Supine position; TFIN: Tissue fraction on inspiratory scan; TFEX: Tissue fraction on expiratory scan; TLC: Total lung capacity; VALI: Ventilator-associated lung injury

\section{Authors' contributions}

$\mathrm{CHL}$ contributed to the conception, design of the study, data analysis, and preparation of this manuscript and is the guarantor of this paper. Both KMS and JWC contributed to the conception, design of the study, data interpretation, data analysis, and manuscript writing. KJC, GYJ, and AE contributed to the study design and data acquisition and revision of the data. $\mathrm{EAH}, \mathrm{CH}$, and $\mathrm{MC}$ contributed to the data interpretation and critical revision of the manuscript. The authors reviewed and approved the manuscript before submission for publication. Special thanks to Ms. Sara Park for the statistical analysis.

\section{Funding}

This research was supported by a Basic Science Research Program through the National Research Foundation of Korea (NRF) funded by the Ministry of Education (2017R1D1A1A09082160) and Korea Environment Industry \& Technology Institute (KEITI) through Environmental Health Action Program, funded by Korea Ministry of Environment (MOE) (2018001360001).

\section{Availability of data and materials}

The datasets used and/or analysed during the current study are available from the corresponding author on reasonable request.

\section{Competing interests}

Eric A. Hoffman is a co-founder and shareholder of the VIDA diagnostics. Other authors declare no conflict of interest.

\section{Author details}

'Department of Radiology, School of Medicine, Kyungpook National University, Kyungpook National University Chilgok Hospital, Daegu, South Korea. ${ }^{2}$ Department of Internal Medicine, School of Medicine, The University of Kansas, Kansas City, Kansas, USA. ${ }^{3}$ Department of Bioengineering, The University of Kansas, Lawrence, Kansas, USA. ${ }^{4}$ Department of Radiology, Research Institute of Clinical Medicine of Jeonbuk National

University-Biomedical Research Institute of Jeonbuk National University Hospital, Jeonju, South Korea. ${ }^{5}$ Department of Radiology, University of lowa, lowa City, USA. ${ }^{6}$ Internal Medicine, University of lowa, lowa City, USA. ${ }^{7}$ Biomedical Engineering, University of lowa, lowa City, USA. ${ }^{8}$ Department of Radiology, Seoul National University College of Medicine, Institute of Radiation Medicine, Seoul National University Hospital, 101 Daehak-ro, Jongnogu, Seoul 03080, South Korea.

Received: 15 May 2020 Accepted: 22 September 2020

Published online: 02 October 2020

\section{References}

1. Guerin C, Gaillard S, Lemasson S, Ayzac L, Girard R, Beuret P, et al. Effects of systematic prone positioning in hypoxemic acute respiratory failure: a randomized controlled trial. JAMA. 2004;292:2379-87.

2. Gattinoni L, Tognoni G, Pesenti A, Taccone P, Mascheroni D, Labarta V, et al. Effect of prone positioning on the survival of patients with acute respiratory failure. N Engl J Med. 2001;345:568-73.

3. Richter T, Bellani G, Scott Harris R, Vidal Melo MF, Winkler T, Venegas JG et al. Effect of prone position on regional shunt, aeration, and perfusion in experimental acute lung injury. Am J Respir Crit Care Med. 2005;172:480-7.

4. Pelosi P, Tubiolo D, Mascheroni D, Vicardi P, Crotti S, Valenza F, et al. Effects of the prone position on respiratory mechanics and gas exchange during acute lung injury. Am J Respir Crit Care Med. 1998;157:387-93.

5. Sud S, Friedrich JO, Adhikari NK, Taccone P, Mancebo J, Polli F, et al. Effect of prone positioning during mechanical ventilation on mortality among patients with acute respiratory distress syndrome: a systematic review and meta-analysis. CMAJ. 2014;186:E381-90.

6. Guerin C, Reignier J, Richard JC. Prone positioning in the acute respiratory distress syndrome. N Engl J Med. 2013;369:980-1.

7. Beitler JR, Shaefi S, Montesi SB, Devlin A, Loring SH, Talmor D, et al. Prone positioning reduces mortality from acute respiratory distress syndrome in the low tidal volume era: a meta-analysis. Intensive Care Med. 2014;40:332-41.

8. Hoffman EA. Effect of body orientation on regional lung expansion: a computed tomographic approach. J Appl Physiol (1985). 1985;59:468-80.

9. Henderson AC, Sa RC, Theilmann RJ, Buxton RB, Prisk GK, Hopkins SR. The gravitational distribution of ventilation-perfusion ratio is more uniform in prone than supine posture in the normal human lung. J Appl Physiol (1985). 2013;115:313-24.

10. Gattinoni L, Taccone P, Carlesso E, Marini JJ. Prone position in acute respiratory distress syndrome. Rationale, indications, and limits. Am J Respir Crit Care Med. 2013:188:1286-93.

11. Prisk GK, Yamada K, Henderson AC, Arai TJ, Levin DL, Buxton RB, et al. Pulmonary perfusion in the prone and supine postures in the normal human lung. J Appl Physiol (1985). 2007;103:883-94.

12. Pappert D, Rossaint R, Slama K, Gruning T, Falke KJ. Influence of positioning on ventilation-perfusion relationships in severe adult respiratory distress syndrome. Chest. 1994;106:1511-6.

13. Galiatsou E, Kostanti E, Svarna E, Kitsakos A, Koulouras V, Efremidis SC, et al. Prone position augments recruitment and prevents alveolar overinflation in acute lung injury. Am J Respir Crit Care Med. 2006;174:187-97.

14. Valenza F, Guglielmi M, Maffioletti M, Tedesco C, Maccagni P, Fossali T, et al. Prone position delays the progression of ventilator-induced lung injury in rats: does lung strain distribution play a role? Crit Care Med. 2005;33:361-7. 
15. Yin $Y$, Hoffman $E A$, Lin CL. Mass preserving nonrigid registration of $C T$ lung images using cubic B-spline. Med Phys. 2009;36:4213-22.

16. Choi S, Hoffman EA, Wenzel SE, Tawhai MH, Yin Y, Castro M, et al. Registrationbased assessment of regional lung function via volumetric $C T$ images of normal subjects vs. severe asthmatics. J Appl Physiol (1985). 2013;115:730-42.

17. Jahani $N$, Yin $Y$, Hoffman EA, Lin CL. Assessment of regional non-linear tissue deformation and air volume change of human lungs via image registration. J Biomech. 2014;47:1626-33.

18. Kaczka DW, Cao K, Christensen GE, Bates JH, Simon BA. Analysis of regional mechanics in canine lung injury using forced oscillations and 3D image registration. Ann Biomed Eng. 2011;39:1112-24.

19. Reinhardt JM, Christensen GE, Hoffman EA, Ding K, Cao K. Registrationderived estimates of local lung expansion as surrogates for regional ventilation. Inf Process Med Imaging. 2007;20:763-74.

20. Gill G, Beichel RR. An approach for reducing the error rate in automated lung segmentation. Comput Biol Med. 2016;76:143-53.

21. Beckmann U, Gillies DM, Berenholtz SM, Wu AW, Pronovost P. Incidents relating to the intra-hospital transfer of critically ill patients. An analysis of the reports submitted to the Australian incident monitoring study in intensive care. Intensive Care Med. 2004;30:1579-85.

22. Lee HJ, Im JG, Goo JM, Kim YI, Lee MW, Ryu HG, et al. Acute lung injury: effects of prone positioning on cephalocaudal distribution of lung inflation--CT assessment in dogs. Radiology. 2005:234:151-61.

23. Cornejo RA, Diaz JC, Tobar EA, Bruhn AR, Ramos CA, Gonzalez RA, et al. Effects of prone positioning on lung protection in patients with acute respiratory distress syndrome. Am J Respir Crit Care Med. 2013;188:440-8.

24. Gattinoni L, Pelosi P, Vitale G, Pesenti A, D'Andrea L, Mascheroni D. Body position changes redistribute lung computed-tomographic density in patients with acute respiratory failure. Anesthesiology. 1991;74:15-23.

25. Tawhai MH, Nash MP, Lin CL, Hoffman EA. Supine and prone differences in regional lung density and pleural pressure gradients in the human lung with constant shape. J Appl Physiol (1985). 2009;107:912-20.

26. Kim SS, Jin GY, Li YZ, Lee JE, Shin HS. CT quantification of lungs and Airways in Normal Korean Subjects. Korean J Radiol. 2017;18:739-48.

27. Amelon R, Cao K, Ding K, Christensen GE, Reinhardt JM, Raghavan ML. Three-dimensional characterization of regional lung deformation. J Biomech. 2011;44:2489-95.

28. Chae KJ, Choi J, Jin GY, Hoffman EA, Laroia AT, Park M, et al. Relative regional air volume change maps at the Acinar scale reflect variable ventilation in low lung attenuation of COPD patients. Acad Radiol. 2020. https://doi.org/10.1016/j.acra.2019.12.004.

29. Albert RK, Keniston A, Baboi L, Ayzac L, Guerin C, Proseva I. Prone positioninduced improvement in gas exchange does not predict improved survival in the acute respiratory distress syndrome. Am J Respir Crit Care Med. 2014; 189:494-6.

30. Broccard A, Shapiro RS, Schmitz LL, Adams AB, Nahum A, Marini JJ. Prone positioning attenuates and redistributes ventilator-induced lung injury in dogs. Crit Care Med. 2000;28:295-303.

31. Constantin JM, Jabaudon M, Lefrant JY, Jaber S, Quenot JP, Langeron O, et al. Personalised mechanical ventilation tailored to lung morphology versus low positive end-expiratory pressure for patients with acute respiratory distress syndrome in France (the LIVE study): a multicentre, single-blind, randomised controlled trial. Lancet Respir Med. 2019;7:870-80,

32. Puybasset L, Cluzel P, Chao N, Slutsky AS, Coriat P, Rouby JJ. A computed tomography scan assessment of regional lung volume in acute lung injury. The CT scan ARDS study group. Am J Respir Crit Care Med. 1998;158:1644-55.

33. Nieszkowska A, Lu Q, Vieira S, Elman M, Fetita C, Rouby JJ. Incidence and regional distribution of lung overinflation during mechanical ventilation with positive end-expiratory pressure. Crit Care Med. 2004;32:1496-503.

34. Xin Y, Cereda M, Hamedani H, Pourfathi M, Siddiqui S, Meeder N, et al. Unstable inflation causing injury. Insight from prone position and paired computed tomography scans. Am J Respir Crit Care Med. 2018;198:197-207.

35. Choi S, Hoffman EA, Wenzel SE, Castro M, Fain S, Jarjour N, et al. Quantitative computed tomographic imaging-based clustering differentiates asthmatic subgroups with distinctive clinical phenotypes. J Allergy Clin Immunol. 2017;140:690-700 e8

36. Rouby JJ, Constantin JM, De AGC R, Zhang M, Lu Q. Mechanical ventilation in patients with acute respiratory distress syndrome. Anesthesiology. 2004; 101:228-34.

37. Malbouisson LM, Busch CJ, Puybasset L, Lu Q, Cluzel P, Rouby JJ. Role of the heart in the loss of aeration characterizing lower lobes in acute respiratory distress syndrome. CT scan ARDS study group. Am J Respir Crit Care Med. 2000;161:2005-12.

38. Guerin C, Beuret P, Constantin JM, Bellani G, Garcia-Olivares P, Roca O, et al. A prospective international observational prevalence study on prone positioning of ARDS patients: the APRONET (ARDS prone position network) study. Intensive Care Med. 2018:44:22-37.

39. Mauri T, Grasselli G, Pesenti A. Systematic assessment of advanced respiratory physiology: precision medicine entering real-life ICU? Crit Care. 2017;21:143.

40. Coxson HO, Mayo JR, Behzad H, Moore BJ, Verburgt LM, Staples CA, et al. Measurement of lung expansion with computed tomography and comparison with quantitative histology. J Appl Physiol (1985). 1995;79:1525-30.

\section{Publisher's Note}

Springer Nature remains neutral with regard to jurisdictional claims in published maps and institutional affiliations.
Ready to submit your research? Choose BMC and benefit from:

- fast, convenient online submission

- thorough peer review by experienced researchers in your field

- rapid publication on acceptance

- support for research data, including large and complex data types

- gold Open Access which fosters wider collaboration and increased citations

- maximum visibility for your research: over $100 \mathrm{M}$ website views per year

At BMC, research is always in progress.

Learn more biomedcentral.com/submissions 